\title{
Neonatal spinal muscular atrophy with diaphragmatic paralysis is unlinked to 5q11.2-q13
}

\author{
G Novelli, F Capon, L Tamisari, E Grandi, C Angelini, P Guerrini, B Dallapiccola
}

\begin{abstract}
Two sibs affected by the severe neonatal form of spinal muscular atrophy (SMA) with diaphragmatic paralysis are described. The two sibs were discordant for the haplotypes determined by DNA markers flanking the SMA locus. This supports non-linkage of SMA to chromosome 5 in this family and indicates that the uncommon SMA type I variant associated with early onset respiratory failure maps outside the 5q11.2-q13.3 region.
\end{abstract}

( $(\mathcal{M}$ Med Genet 1995;32:216-219)

Spinal muscular atrophy (SMA) is a group of autosomal dominant, $\mathrm{X}$ linked, and autosomal recessive diseases with severe, intermediate, or mild phenotypes. ${ }^{1}$ The autosomal recessive forms (MIM 253300, MIM 253400, MIM 253550) are classified as type I, type II, and type III according to clinical manifestations and age of onset. ${ }^{23}$ Linkage analysis has assigned these three forms to chromosome 5q11.2-q13.3. ${ }^{4-6}$ The localisation of the SMA locus has allowed prenatal diagnosis in at risk families with at least one affected child. ${ }^{7-9}$ It has been estimated that only $5 \%$ of all SMA type I families are not linked to $5 \mathrm{q} .{ }^{89}$ However, definite proof of this figure is still lacking and other authors suggest that a consistently higher proportion of SMA type I cases are unlinked to $5 \mathrm{q}^{8}{ }^{810}$ Cobben et $a l^{11}$ reported a family which suggested the existence of a second locus for autosomal recessive SMA type I. We report on two sibs, born to unaffected parents, with neonatal SMA type I associated with early onset respiratory distress related to diaphragmatic paralysis, in which DNA analysis suggested non-linkage to chromosome $5 \mathrm{q}$.

\section{Case reports}

CASE 1

A $3200 \mathrm{~g}$ female infant was delivered at term to a primiparous 28 year old woman. The parents were healthy and unrelated with no history of muscle disorders. At birth, the infant appeared apnoeic without response to stimuli and was immediately intubated. Cyanosis cleared promptly with bag ventilation with $21 \%$ oxygen but several attempts at extubation failed because of lack of respiratory effort, and, therefore, mechanical ventilation needed to be undertaken. There was no evidence of skeletal muscle weakness and deep tendon reflexes were normal. Chest radiological evaluation showed marked raising of both hemidiaphragms with absence of diaphragmatic motion on fluoroscopy (fig 1).

At 2 months of age, the baby was still unable to ventilate and clinical evidence of progressive muscular weakness was present. At 3 months of age, muscle wasting, lingual fasciculations, hypotonia, absent motility, and areflexia were clearly indicative of a severe neuromuscular impairment. Limb muscle weakness was predominantly distal with paralysis of the extensors of the hands and feet. The arms were abducted and internally rotated at the shoulders assuming a "jug handle" position. There was a gradual decrease in leg movements with bilateral development of pes equinus. Respiratory failure was associated with a narrowed thorax, pectus excavatum, and flaring of the lower ribs. Feeding and swallowing were impossible.

Muscular enzymes were only slightly raised (CK $230 \mathrm{IU} / 1$ and LDH $462 \mathrm{IU} / \mathrm{l}$ ). An elec-

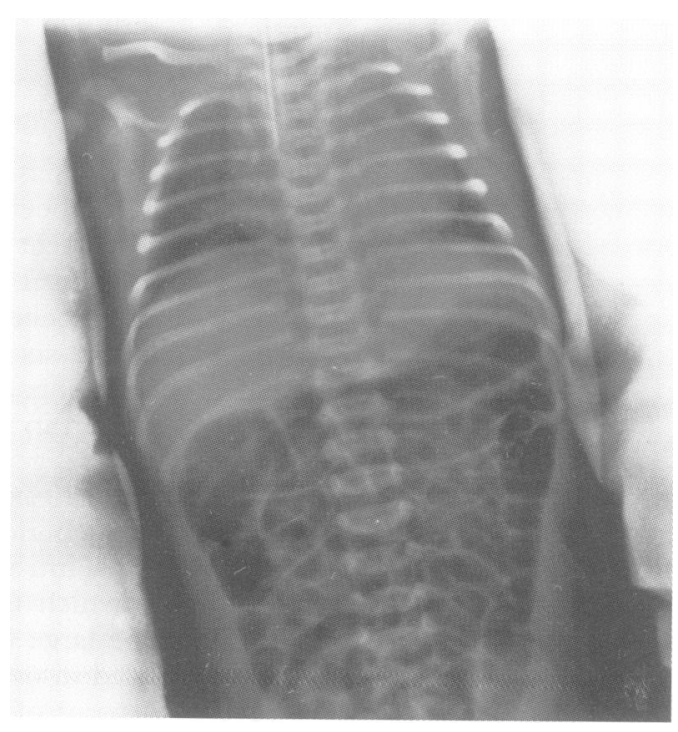

Figure 1 Case 1 . Frontal chest $x$ ray showing raising of both hemidiaphragms. 


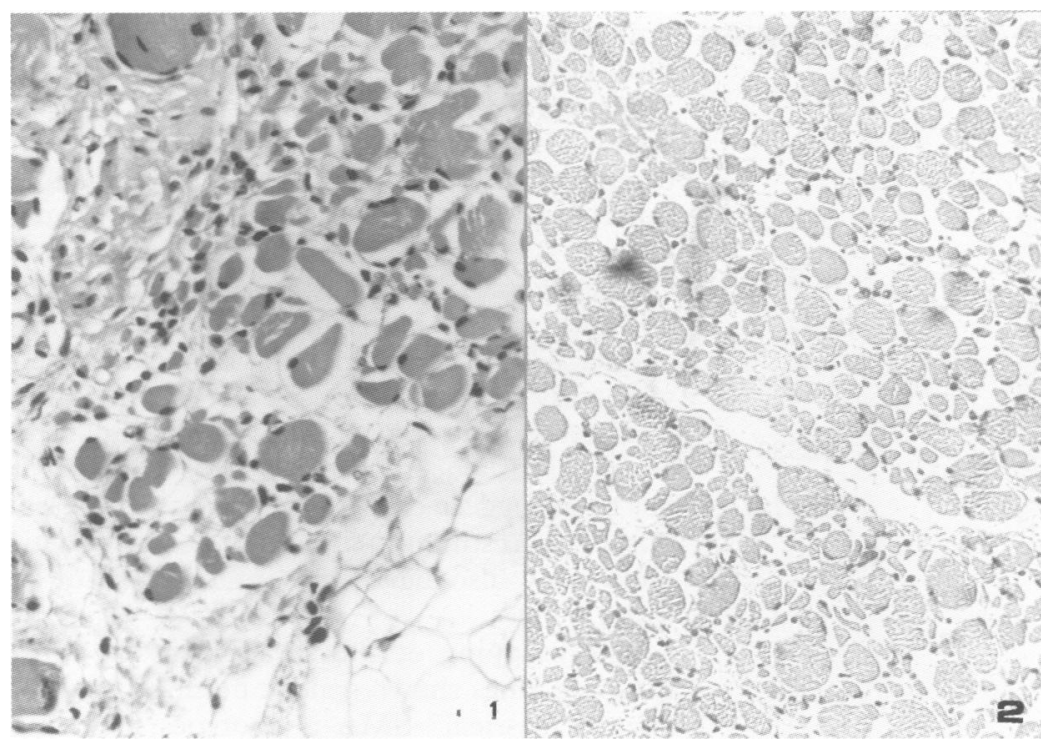

Figure 2 Intercostal muscle: comparison of cases 1 and 2 (HE) shows the histological change in time of neurogenic atrophy. Increase of anisocytosis of muscle fibres and fat infiltration are evident. unusually high diaphragm bilaterally (data not shown). Clinical and radiological features were highly suggestive of the same disease documented in the dead first sib. Therefore it was decided that respiratory support by mechanical ventilation was not indicated, and the infant died one hour after birth.

A muscle biopsy of the left quadriceps showed groups of atrophic and scattered normal fibres (data not shown).

Necropsy showed a markedly raised thin and velar diaphragm. Histological examination of different skeletal muscles showed large groups of atrophic fibres (fig 2). This pattern was most severe in the diaphragm in which a few normal sized fibres were visible. The brain and cerebral bulb appeared normal. Histological examination of the thalamus, cerebral bulb, and medulla oblongata showed severe neuronal loss, especially in the anterior horns. A few of the remaining neurones showed marked enlargement and degenerative changes associated with occasional neuronophagia (data not shown).

tromyogram showed no fibrillation at rest but small groups of fibres were discharging during movement and this was considered consistent with the diagnosis of diffuse denervation. Nerve stimulation of IPS and EPS showed a reduction of the registered MAP.

A biopsy of the left quadriceps was performed and studied using histological, histochemical, and histoenzymatic techniques. The presence of clusters of large rounded fibres and scattered atrophic fibres is consistent with SMA.

The patient died at 7 months of age after several episodes of pneumonia. Necropsy showed widespread neurogenic atrophy of skeletal muscle (fig 2). The diaphragm was thin and membranes showed severe reduction of discernible muscle fibres. Macroscopic appearance of the pons, cerebral bulb, and spinal cord was markedly atrophic (data not shown). There was a severe depletion of the number of anterior horn cells associated with degenerative changes, neuronophagia, and gliosis (fig 3).

The patient was originally diagnosed as having SMA type I and the mother asked for prenatal diagnosis in the second pregnancy. The parents were informed of the limitations of prenatal diagnosis based on a linkage analysis in nuclear SMA families. ${ }^{912}$ Notwithstanding this, the mother requested first trimester monitoring of the fetal genotype and continued the pregnancy.

\section{CASE 2}

A $3300 \mathrm{~g}$ male infant was delivered after an uneventful pregnancy at 41 weeks of gestation. At one minute, the Apgar score was 2 and the baby was intubated. At five minutes, the Apgar score was 7 but there was no respiratory effort and manual ventilation was needed. On initial examination, bilateral fixed flexion of the elbow and wrist joints with ulnar deviation of the hands was noted. The infant was hypotonic, with absent tendon reflexes and a weak response to stimuli. A chest $x$ ray showed an

\section{DNA STUDIES}

DNA from a frozen biopsy of case 1 was available and used for molecular analysis, according to Lo Cicero et al. ${ }^{9}$ Genomic DNA from a chorionic villus sample (CVS) was obtained at 12 weeks during the mother's second pregnancy and indirect prenatal diagnosis was performed using a set of microsatellite markers flanking the SMA locus on $5 \mathrm{q}^{9}{ }^{9}$

The results of the DNA analysis are shown in fig 4. Complete informativity was obtained using the markers D5S125, D5S435, D5S557, D5S39, and D5S127. This analysis predicted that the fetus had a wild type genotype, having

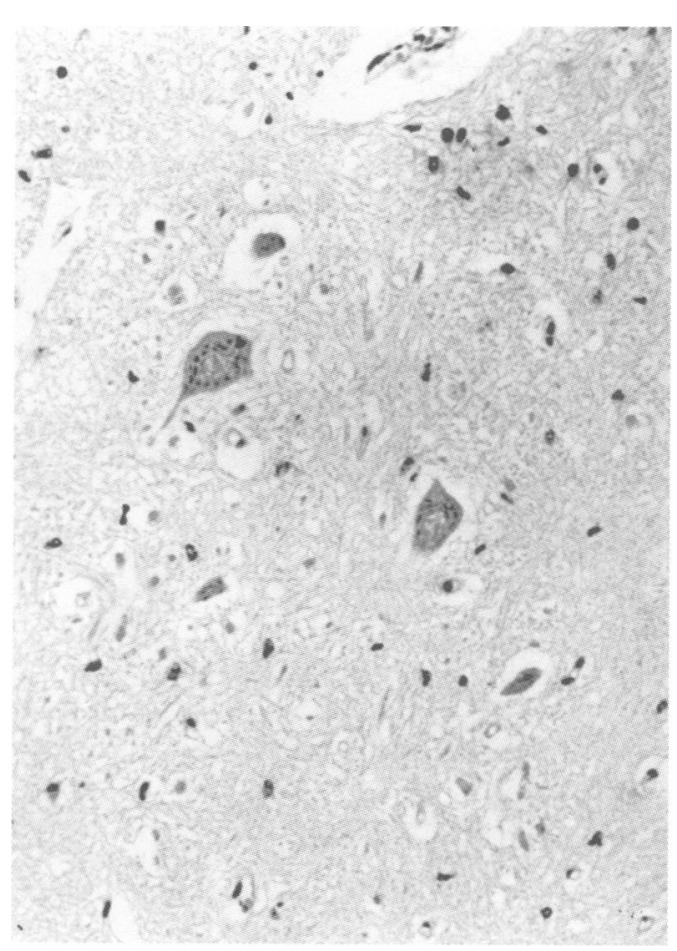

Figure 3 Case 1: region of cervical spinal cord showing severe neuronal loss with degenerative changes of the remaining neurones (HE). 


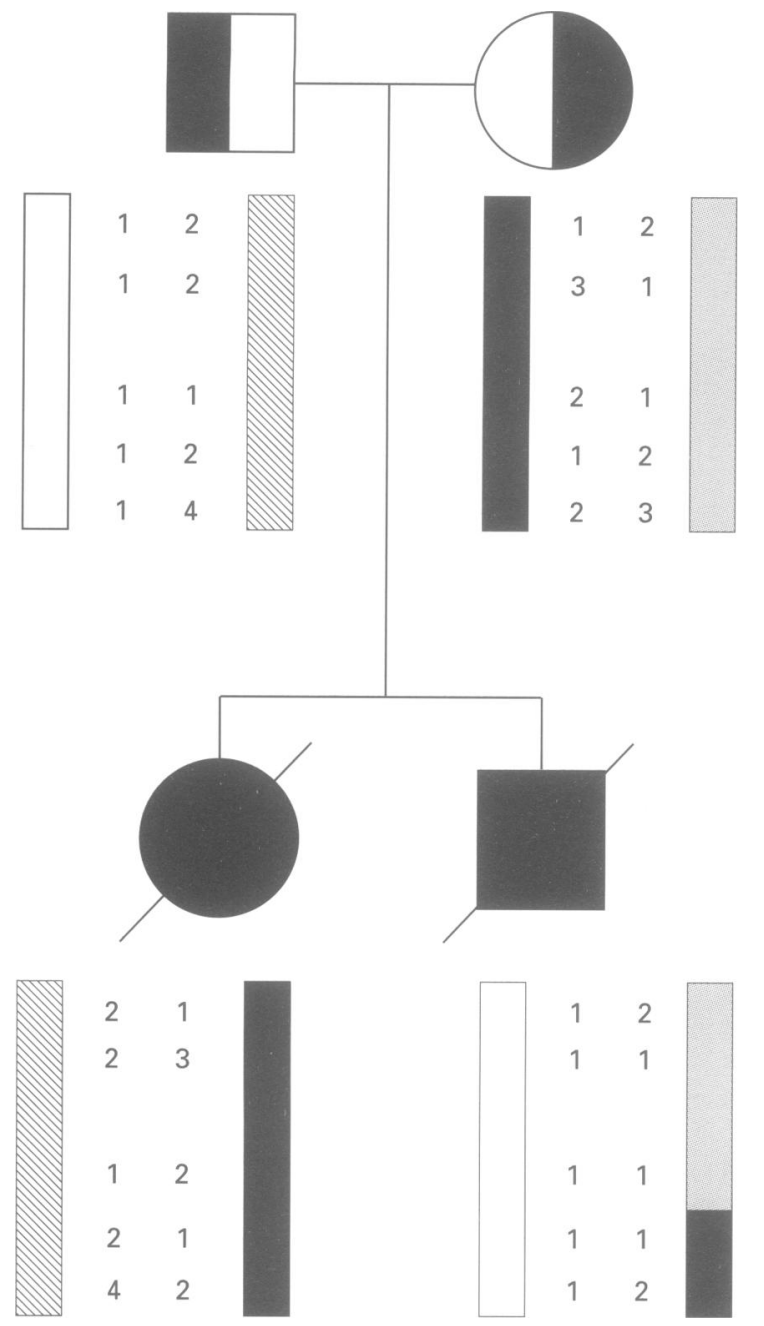

Figure 4 Pedigree and DNA results in the family. The numbers under the pedigree symbols refer to alleles of the DNA markers D5S125, D5S435, D5S557, D5S39, and D5S127.9 The SMA locus on $5 q$ is located between D SS435 and D5S557.

inherited the parental haplotypes unlinked to the chromosome 5q SMA locus. A recombination event was also detected between D5S112 and D5S39, which was not considered relevant because it was outside the SMA locus (fig 4, II.2) Microsatellite alleles were re-evaluated in lymphocyte and fibroblast DNA of the newborn (case 2), and complete concordance with the CVS results was obtained. This excludes misdiagnosis owing to laboratory contamination, sampling errors, or PCR artefacts. Paternity testing using three DNA polymorphisms (D1S80, APOB, HLADQ $\alpha$ ) was performed and showed no evidence of nonpaternity. ${ }^{13}$

\section{Discussion}

Severe neonatal respiratory failure, associated with radiological evidence of bilateral diaphragmatic weakness and eventration, is not a typical feature of SMA type I. On the other hand, the diagnostic criteria of SMA, reported by the International SMA Consortium, ${ }^{14}$ do not exclude SMA patients with diaphragmatic paralysis. In the first patient, clinical manifestations of Werdnig-Hoffmann disease became apparent at 2 months of age, but some limb deformities suggestive of a neuromuscular disorder were present in the second sib at birth. The diagnosis of SMA was confirmed in both instances by muscle biopsy and postmortem examination that showed (1) neurogenic muscle atrophy; (2) decrease in the motor neurones of the anterior horns of the spinal cord; (3) degenerative changes and neuronophagia; and (4) proliferation of astrocytes and microglia. This unique variant of SMA, associated with early respiratory muscle involvement and weakness and atrophy of the distal musculature, has previously been observed. ${ }^{15-19}$ Moreover, it has been suggested that other infants with early onset fatal respiratory disease of unknown aetiology may also have this unusual variant of SMA. ${ }^{20}$

The mapping of the SMA locus to chromosome 5 has shown genetic homogeneity between "classical" SMA phenotypes including the severe form or Werdnig-Hoffmann disease, the mild form or Kugelberg-Welander disease, and the intermediate type III form. This has ruled out non-allelic heterogeneity to explain the interfamilial and intrafamilial clinical heterogeneity. ${ }^{82122}$ In the absence of significant genetic heterogeneity within the autosomal recessive SMAs, the DNA markers in the chromosomal region 5q12-13 are usually used for prenatal and presymptomatic diagnosis in informative families. ${ }^{912324}$ A prenatal risk calculation which includes genetic heterogeneity can be applied and is acceptable in the majority of cases. ${ }^{912}$ However, the recent observation of SMA type I unlinked to $5 q$ and the occurrence of de novo deletions of the $5 \mathrm{q} 13$ region indicate the need for caution in interpreting the results provided by linkage studies. ${ }^{8112526}$

The family reported in the present study is unlinked to chromosome $5 \mathrm{q}$ markers. This indicates that the rare SMA variant associated with paralysis of the diaphragm maps outside the $5 \mathrm{q} 11.2-\mathrm{q} 13.3$ region. It also implies that this clinical form is genetically different from "classical" SMA types. The two sibs of the present family had inherited the four parental chromosomes 5, excluding recombination events. Furthermore, clinical features were distinct from those expected to occur in other autosomal recessive diseases associated with eventration of the diaphragm or in other similar progressive motor neurone diseases. ${ }^{18}$

This finding has relevant implications for genetic counselling and prenatal diagnosis in SMA families.

We thank Dr E Bertini for the useful discussion. This work was supported by Telethon Italy (Grant no 296), ASM (Milan), and MURST $(40 \%$ and $60 \%)$.

1 Dubowitz V. Muscle disorders in childhood. Philadelphia: Saunders, 1978.

2 Dubowitz V. Chaos in classification of the spinal muscular atrophies of childhood. Neurmusc Disord 1991;1:47-53. atrophies of childhood. Neuromusc Disord $1991,1: 47-53$.
Rudnik-Schöneborn S, Röhring D, Morgan G, Wirth B,
Zerres K. Autosomal recessive proximal spinal muscular atrophy in 101 sibs out of 48 families: clinical picture, influence of gender, and genetic implications. Am F Med Genet 1994,51:70-6.

Brzustowicz LM, Lehner T, Castilla LH, et al. Genetic mapping of chronic childhood-onset spinal muscular atrophy to chromosome 5q11.2-13.3. Nature 1990;344:540-

5 Melki J, Abdelhak S, Sheth P, et al. Gene for chronic proximal spinal muscular atrophies maps to chromosome
5q. Nature 1990;344:767-8. 
6 Gilliam TC, Brzustowicz LM, Castilla LH, et al. Genetic homogeneity between acute and chronic forms of spinal muscular atrophy. Nature 1990;345:823-5.

7 Daniels RJ, Suthers GK, Morrison KE, et al. Prenatal prediction of spinal muscular atrophy. $\mathcal{F}$ Med Genet 1992; 29:165-70.

8 Mérette C, Brzustowicz LM, Daniels RJ, et al. An investigation of genetic heterogeneity and linkage disequilibrium in 161 families with spinal muscular atrophy.

Lo Cicero S, Capon F, Melchionda S, et al. First-trimester prenatal diagnosis of spinal muscular atrophy using microsatellite markers. Prenat Diagn 1994;14:459-62.

10 Lunt PW, Mathew C, Clark S, et al. Can prenatal diagnosis be offered in neonatal lethal spinal muscular atrophy (SMA) with arthrogryposis and fractures? $\mathcal{f}$ Med Genet 1992;29:282A.

11 Cobben JM, Scheffer H, de Visser M, et al. Apparent SMA I unlinked to 5q. $\mathcal{F}$ Med Genet 1994;31:242-4.

12 Husschenbett J, Hanke R, Pfeifer L, Speer A. Prenatal diagnosis of the acute form of proximal spinal muscular atrophy: experience on the acceptance of linkage analyses by the families. Prenat Diagn 1993;13:643-9.

13 Novelli G, Spinella A, Gennarelli M, Mingarelli R, Dallapiccola B. Analysis of APOB, HLADQalpha, and D1S80 polymorphisms in the Italian population using the polypolymorphisms in the Italian population using the poly-
merase chain reaction. Am $₹$ Hum Biol 1992;4:381-6.

14 Munsat TL. International SMA collaboration. Workshop report. Neuromusc Disond 1991;1:81.

15 Mellins RB, Hays AP, Gold AP, et al. Respiratory distress as initial manifestation of Werdnig-Hoffmann disease.

16 Schapira D, Swash M. Neonatal spinal muscular atrophy presenting as respiratory distress: a clinical variant. Muscle Nerve 1985;8:661-3.
17 Bove KE, Iannaccone ST. Atypical infantile spinomuscular atrophy presenting as acute diaphragmatic paralysis. Pediatr Pathol 1985;8:95-107.

18 Bosman C, Bachelet V, Boldrini R, Bertini E. Diaphragmatic paralysis due to partial diaphragmatic hypoplasia mimicking a localised muscular dystrophy: a case report. Clin Neuropathol 1988;7:33-8.

19 Bertini E, Gadisseux JL, Palmieri G, et al. Distal infantile spinal muscular atrophy associated with paralysis of the diaphragm: a variant of infantile spinal muscular atrophy. Am f Med Genet 1989;33:328-35.

20 McWilliam RC, Gardner-Medwin D, Doyle D, Stephenson JBP. Diaphragmatic paralysis due to spinal muscular atrophy. An unrecognised cause of respiratory failure in infancy? Arch Dis Child 1985;60:145-9.

21 Munsat TL, Skerry L, Korf B, et al. Phenotypic heterogeneity of spinal muscular atrophy mapping to chromosome 5q11.2-q13.3(SMA5q). Neurology 1990;50 520-7.

22 Brzustowicz LM, Mèrette C, Kleyn PW, et al. Assessment of non-allelic genetic heterogeneity of chronic (type II and III) spinal muscular atrophy. Hum Hered 1993;43:380-7.

23 Melki J, Abdelhak S, Burlet P, et al. Prenatal prediction of Werdnig-Hoffmann disease using linked polymorphic DNA probes. F Med Genet 1992;29:171-4.

24 Matilla T, Corral J, Miranda M, et al. Prenatal diagnosis of Werdnig-Hoffmann disease: DNA analysis of a mummified umbilical cord using closely linked microsatellite markers. Prenat Diagn 1994;14:219-22.

25 Melki J, Lefebre, Burglen L, et al. De novo and inherited deletions of the $5 \mathrm{q} 13$ region in spinal muscular atrophies. Science 1994;264:1474-7.

26 Capon F, Lo Cicero S, Levato C, Novelli G, Dallapiccola $B$. De novo deletions in $5 \mathrm{q} 13$ region and prenatal diagnosis of spinal muscular atrophy. Prenat Diagn (in press). 